Philippine Journal of Psychology, 2018, 51(1), 1-20

Copyright @ 2018 Psychological Association of the Philippines

\title{
Construct Validation of Ryff's Psychological Well-being Scale: Evidence From Filipino Teachers in the Philippines
}

\author{
Jonalyn B. Villarosa \\ Palawan State University \\ Fraide A. Ganotice, Jr. \\ Palawan State University \\ Hong Kong Shue Yan University
}

\begin{abstract}
Research on psychological well-being has given attention to employees in various industries but research involving teachers particularly in non-Western contexts remains scarce. Using both within- and betweennetwork validation approaches, this study attends to gaps in literature through the examination of the psychometric properties of 42-item Ryff's Psychological Well-being Scale - a theory-derived scale which taps six core dimensions of psychological well-being: autonomy, environmental mastery, personal growth, positive relations with others, purpose in life, and self- acceptance. Through confirmatory factor analysis, data from 237 Filipino teachers provide support for the a priori six-factor model although a number of items obtained poor factor loadings. Betweennetwork analysis suggests that these dimensions are linked to job performance. Findings are discussed in relation to the development of potential research agenda using the scale in the Philippine context.
\end{abstract}

Keywords: psychological well-being, job performance, confirmatory factor analysis

Correspondence concerning this article can be addressed to Jonalyn Villarosa, College of Teacher Education, Palawan State University, Puerto Princesa City. Email: jonalyn5300@gmail.com

Editor Note: This paper was accepted for publication under the term of the previous Editor, Margaret Udarbe-Alvarez. 
Theory and research regard psychological well-being not only as a key determinant of employee performance but also as a useful concept for understanding employees' organizational behaviors in various settings (Ryff, 2014). Because of this, the investigation of employees' well-being has gained research momentum in the past decade where various studies were realized with respect to mapping its antecedents and consequences in various contexts (see for example Huppert, Baylis, \& Keverne, 2005; McInerney, Ganotice, King, Morin, \& Marsh, 2014; Ryff \& Singer, 2006). It is possible that the dynamics of employee experiences caught researchers' attention motivating them to pay a great deal of research attention to understanding various aspects of employees' psychological well-being (Seligman \& Csikszentmihalyi, 2000). Little is known, however, about the interplay of various factors in the development and consequences of psychological well-being of teachers, especially in non-western countries like the Philippines.

The promotion of psychological well-being in workplaces is consistent with positive psychology framework where premium is given to the concept of well-being (Seligman, 2011). Ryan and Deci (2001, p.142) stated that "the concept of well-being refers to optimal psychological functioning and experience" and is construed to have underlying dimensions (e.g., subjective, social, and psychological, health-related dimensions) (Sears, 2013). With regard to this, Seligman (2011) proposed a well-being model which consists of positive emotion, engagement, relationships, meaning, and achievement (PERMA). Researchers have shown particular interest in studying psychological well-being (PWB) because of its relationship with various outcomes. For example, PWB has been linked to dramatic improvement of employee productivity (Sears, Shi, Coberley, \& Pope, 2013), talent retention (Fredrickson, 2001), commitment (McInerney et al., 2014) and even to better health (Gandy, Carter, Pope, \& Rula, 2014; Vasquez, Hervas, Rahona, \& Gomez, 2009). While well-being literature has grown exponentially, there is limited understanding, however, of how this construct is applied in the teaching profession. This lesser amount of attention paid to psychological well-being of teachers has to be addressed considering the various factors that confront teachers as they carry out the mandates of their profession, which can potentially take a toll on their well-being. In fact, literature 
demonstrates that improved teachers' well-being relates significantly with students' achievement gains both academically and behaviorally (Esposito, 1999; Haynes, Emmons, \& Ben-Avie, 1997; Hoy, Hannum, \& Tschannen-Moran, 1998). Teachers' well-being therefore is of paramount importance if nurturing similar constructs is aimed among students. In view of these, psychological well-being construct involving teachers is an important psycho-educational construct that needs closer examination. This examination should start from a closer look into the acceptability of the measure when used in a different context other than the population in which it was originally designed. Validation of well-being instruments is necessary especially when the outcomes are used to formulate school policy recommendations.

Ryff (1989) formulated a theory-based psychological well-being scale (PWBS) noted for eudaimonic conceptions of happiness which captured various perspectives in one measurement model. She distinguished core dimensions of psychological well-being through a 42-item scale construed to be multidimensional. Since the inception of PWBS, researchers have checked the validity of the scale in different countries, such as in New Zealand (Hone, Jarden, \& Schofield, 2014), Portugal (Silva \& Caetano, 2011), and Japan (Kishida et al., 2004). From these studies, it appears that these generally involved employees from industries and studies involving teachers have been sidelined. As Kállay and Rus (2014, p. 20) noted, there is a "need of more studies aiming to examine how this instrument works in other cultures than that in which it was developed." This study therefore responds to this invitation by examining the acceptability of Ryff's PWBS involving Filipino teachers in the Philippines.

The literature is explicit in promoting the importance of examining the psychometric elements of adapted instruments before they are used in different contexts. For example, Maneesriwongul and Dixon (2004) underscored that cross-cultural validity of the adapted instruments needs to be established before their use in a context other than the population it was originally designed to serve. It is not unlikely that the scale developed specifically for a certain cultural group may not work when used among other groups (see also Fischer 2004; Hambleton 2001). Specific to the validation of PWB, Kállay \& Rus (2014, p. 20) posed an invitation to further validate this scale: "we emphasize the 
need of more studies aiming to examine how this instrument works in other cultures than that in which it was developed."

\section{Ryff's Psychological Well-being Scale}

Consistent with the need to define the structure of psychological well-being items, Ryff has proposed a multidimensional model of psychological well-being based on her reviews of theories and perspectives in psychology. Ryff's (2014) model taps the following six core dimensions: autonomy (living in accordance to own convictions), environmental mastery (management of life situations), personal growth (the use of talents and potentials), positive relations with others (quality relationships with significant others), purpose in life (meaning, purpose, and directions which participants identified for themselves), and self-acceptance (acceptance and awareness of limitations).

Empirical studies examined the validity and reliability of the scale in western samples including the Swedish (Lindfors, Berntsson, \& Lundberg, 2006), Italian (Sirigatti et al., 2009), and Spanish (e.g., van Dierendonck, Díaz, Rodríguez-Carvajal, Blanco, \& Moreno-Jiménez, 2008) and Asian samples like the Chinese (e.g., Cheng \& Chan, 2005). Despite these, Ryff's model has drawn serious doubts on the acceptability of her model. For example, the strong correlation of some dimensions in her scale were interpreted as a sort of overlap between subscales; hence, items found to have content overlap are suggested to be removed from the item pool (see for example Abbott \& Sapsford, 2006; Cheng \& Chan, 2005).

\section{Within-network and Between-network Validation}

Like various validation studies (Ganotice, Downing, Mak, Chan, \& Lee, 2015; King \& Ganotice, 2013; King, Ganotice, \& McInerney, 2012), this study adopts a construct validation approach (Marsh, 1997) in examining the underlying structures of Ryff's Psychological WellBeing Scales as applied to academic contexts. Central to this approach is the use of either within-network (internal construct validation) or between-network studies (external construct validation). Within- 
network construct validation can be performed by examining the intercorrelation of factors that compose a scale and through confirmatory factor analysis (CFA); whereas between-network construct validation can be performed by correlating the factors to other external theoretically-relevant factors.

Both within- and between-network approaches were used in this study to make the procedure more robust. In application, withinnetwork approach was used by using confirmatory factor analysis in examining the six-factor structure of the PWBS. To establish betweennetwork validity, the correlation of PWB factors with indices of job performance were examined. The assumption was that the six PWB factors will be positively related to job performance.

Validation of PWB scale in the Philippines represents an opportunity to investigate the well-being of Filipino teachers. Specifically, this study was conducted for three important reasons. First, teaching is believed to be one of the most stressful occupations (Johnson et al., 2005; Travers \& Cooper, 1996). The literature demonstrates that sources of teacher stress include work overload, non-collaboration with colleagues, inadequate administrative support, students' behavioral management, among others (e.g., Kyriacou, 2001). There is strong reason to believe that Filipino teachers share work-related stress that may influence their psychological well-being. Although there has been no systematic report on the psychological wellbeing of Filipino teachers, some relevant reports involving Filipino teachers suggest that they are not free from stress (see for example Gamboa, 2014; Torrevillas, 2013). Second, results of previous studies on the acceptability of Ryff's PWBS have been mixed or inconsistent. While a number of studies provided support to six-factor well-being conceptualization (e.g., Cheng \& Chan, 2005; Clarke, Marshall, Ryff, \& Wheaton, 2001; Sirigatti et al., 2009), some studies yielded contradictory results that challenge the acceptability of six-factor PWB model (e.g., Abbot \& Wallace, 2010; Kafka \& Kozma, 2002; Springer \& Hauser, 2006). This study therefore is a test of generalizability of Ryff's multidimensional well-being conceptualization in Asia. Third, while PWBS has been validated in various cultures, it seems apparent that some studies failed to take into account the importance of including external but theoretically-relevant criteria in establishing 
the validity of a scale (e.g., Kállay \& Rus, 2014). This study attends to this limitation by considering a wider array of theoretically relevant criteria within which to establish criterion-related validity. Finally, this study involved a sample of Filipino teachers from the Philippines. Thus, it represents one of very few examinations of Ryff's PWBS in a non-western context. This study will highlight the acceptability of PWBS in Asia.

\section{The Present Study}

The study aims to investigate psychometric properties of Ryff's Psychological Well-being Scale when used by Filipino teachers in the Philippines using both within- and between-network validation approach. Specifically, the following objectives guided the analysis:

a) assess the within-network construct validity of Ryff's Psychological Well-being Scale through confirmatory factor analysis;

b) examine its between-network construct validity through correlations with theoretically relevant constructs such as job performance as indexed by interpersonal facilitation, job dedication, and task performance; and

c) examine if psychological well-being accounts for a significant amount of variance in predicting teachers' job performance.

Job performance, operationalized in terms of interpersonal facilitation, job dedication, and task performance, was selected because of its relationships with PWB in the existing literature (e.g., Diener, 2009; Ryff, 1989; Ryff \& Singer, 1998). It is hypothesized that PWB will have a positive relationship with job performance.

\section{METHOD}

\section{Participants}

A total of 237 teachers from two state-owned universities answered the self-report questionnaire. There were 166 (70\%) females and $71(30 \%)$ males and the average age was 36.54 years $(S D=11.11$; min age $=21$, max age $=67)$. Of these teachers, $26(11 \%)$ completed 
doctorate degrees, 92 (40.5\%) completed masters' degrees, and 115 (48.5\%) completed college degrees. There were 213 or $90 \%$ assigned in college level, 11 or $4.6 \%$ assigned in secondary level, and 13 or $5.5 \%$ assigned in primary level.

\section{Measures}

Psychological well-being. This variable was measured using the 42-item Psychological Well-Being Scale (Ryff, 1989) with six dimensions: self-acceptance (7 items; e.g., "In general, I feel confident and positive about myself"), purpose in work/life (7 items; e.g., "I am an active person in carrying out the plans I set for myself at work"), personal growth (7 items; e.g., "I have the sense that I have developed a lot as a person through my work"), positive work relations with others (7 items; e.g., "I enjoy personal and mutual conversations with the people I work with"), environmental mastery ( 7 items; e.g., "I am quite good at managing the many responsibilities of my daily work life"), autonomy (7 items; e.g., "My work decisions are not usually influenced by what everyone else at work is doing"). Participants responded in a scale from 1 (strongly disagree) to 6 (strongly agree).

Job performance. This variable was measured using a 15-item Contextual Performance Questionnaire (Van Scotter \& Motowidlo, 1996) with the following subscales: job dedication (e.g., "I put extra hours to get work done on time"), task performance (e.g.,"I usually work harder than usual/necessary"), and interpersonal facilitation (e.g., "I praise my colleagues when they are successful"). Items were rated on a 6-point Likert scale from 1 (low agreement) to 6 (high agreement).

\section{Data Analysis}

Measures of descriptive statistics like mean, standard deviation, and critical ratio of skewness were computed. Then, we followed the two-step approach of Anderson and Gerbing (1988) to test our hypothesized structural equation model (SEM). The first step involved assessing a measurement model wherein all variables served as latent constructs with its parcels as indicators through CFA. Several 
fit indices recommended by $\mathrm{Hu}$ and Bentler (1999) were considered in the examination of validity of the said measurement model. The fit indices include the following: a) non-significant chi square test statistic; b) goodness of fit index (GFI), comparative fit index (CFI), Tucker Lewis Index (TLI), and Normed Fit Index (NFI) values should be greater than .90; and c) Root mean square error of approximation (RMSEA) value should be less than .08. Additionally, simultaneous regression was performed to clarify the amount of variance explained by the six dimensions of PWB to outcomes (job performance).

\section{RESULTS}

\section{Preliminary Analysis}

Normality was assessed by examining skewness and kurtosis values for each item. Considering the PWB items, skewness ranged from -1.27 to 0.84 , while kurtosis ranged from -1.35 to 0.93 which are within the acceptable range (Finney \& DiStefano, 2006). Internal consistencies of the subscales of PWB Scale were satisfactory: autonomy $\mu=.79$, environmental mastery $\mu=.62$, personal growth $\mu$ $=.85$, positive relation with others $\mu=.74$, purpose in life $\mu=.78$, and self-acceptance $\mu=.66$. Other subscales used to establish the criterionrelated validity showed high internal consistencies: interpersonal facilitation $\mu=.90$, job dedication $\mu=.90$, and task performance $\mu$ $=.87$. The means, standard deviations, Cronbach's alpha coefficients, and zero-order correlations of study variables are reported in Table 1.

An examination of the zero-order correlations of the six PWB subscales indicates that they are positively correlated with one another (range $=.24$ to $.61, p<.001$ ). For example, autonomy was positively related to environmental mastery $(r=.47)$, personal growth $(r=.34)$, positive relation with others $(r=.54)$, purpose in life $(r=.27)$, and self-acceptance $(r=.24)$.

\section{Within-network Construct Validity}

A priori model with six latent factors (autonomy, environmental mastery, personal growth, positive relations with others, purpose in 


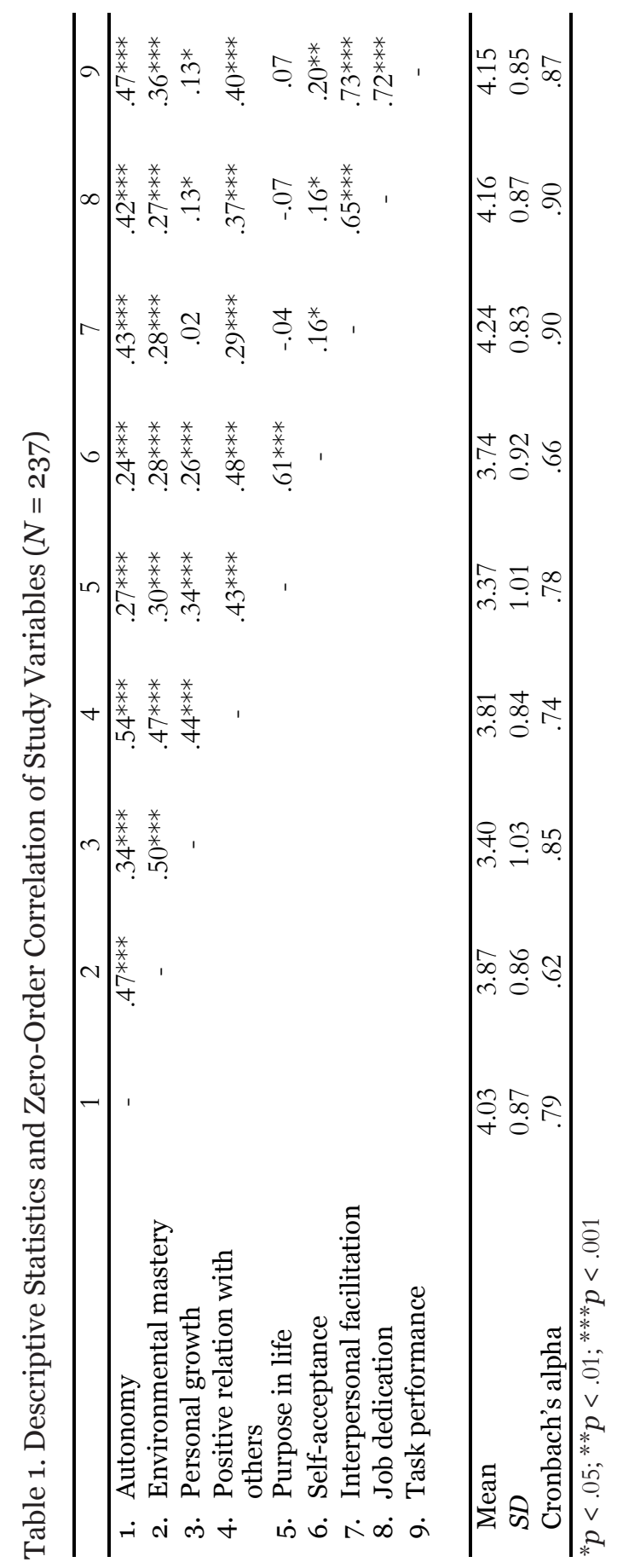


life, and self-acceptance) was examined through CFA. This model did not fit the data well where various items displayed factor loadings less than .34 (Stevens, 2002) and standardized residuals greater than 2.58 (Byrne, 1998). To improve the fit of the measurement model, items with factor loadings less than .34 and standardized residuals of greater than 2.58 were eliminated in the scale.

Once the 24 poorly fitting items were removed, the shorter 18 item model with three items per dimension was evaluated using the same data set. An improved model fit was observed. Results indicated that the model had a good fit to the data: $\chi^{2}=263.632 ; \mathrm{df}=119 ; p=$ $.000, \chi^{2} / \mathrm{df}=2.22 ; \mathrm{CFI}=.92 ; \mathrm{GFI}=.90 ; \mathrm{TLI}=.91 ; \mathrm{RMSEA}=.07$. Only the chi-square statistic was not satisfactory.

\section{Between-network Construct Validity}

The examination of between-network construct validity was similar to the examination of criterion-related validity. To do this, the latent correlations of the six dimensions of Ryff's PWB with job performance using CFA were examined. Job performance was posited as a latent construct underpinned by interpersonal facilitation, job dedication, and task performance. Results showed that the latent correlations of various dimensions of PWB with external measures were generally within the acceptable direction. For example, autonomy was positively correlated to the three indicators of job performance: interpersonal; facilitation, job performance, and task performance (from 42 to .47, $p$ <.001). A similar pattern of relationship is found among environmental mastery, positive relation with others, selfacceptance and the external measures.

\section{Psychological Well-being as Predictor of Job Performance}

Multiple regression analyses were used to test if the six wellbeing dimensions can significantly predict teachers' job performance: interpersonal facilitation, job dedication, and task performance. Results indicated that three predictors explained 30\% - 40\% of variance in predicting various dimensions of job performance (refer to Table 2). 


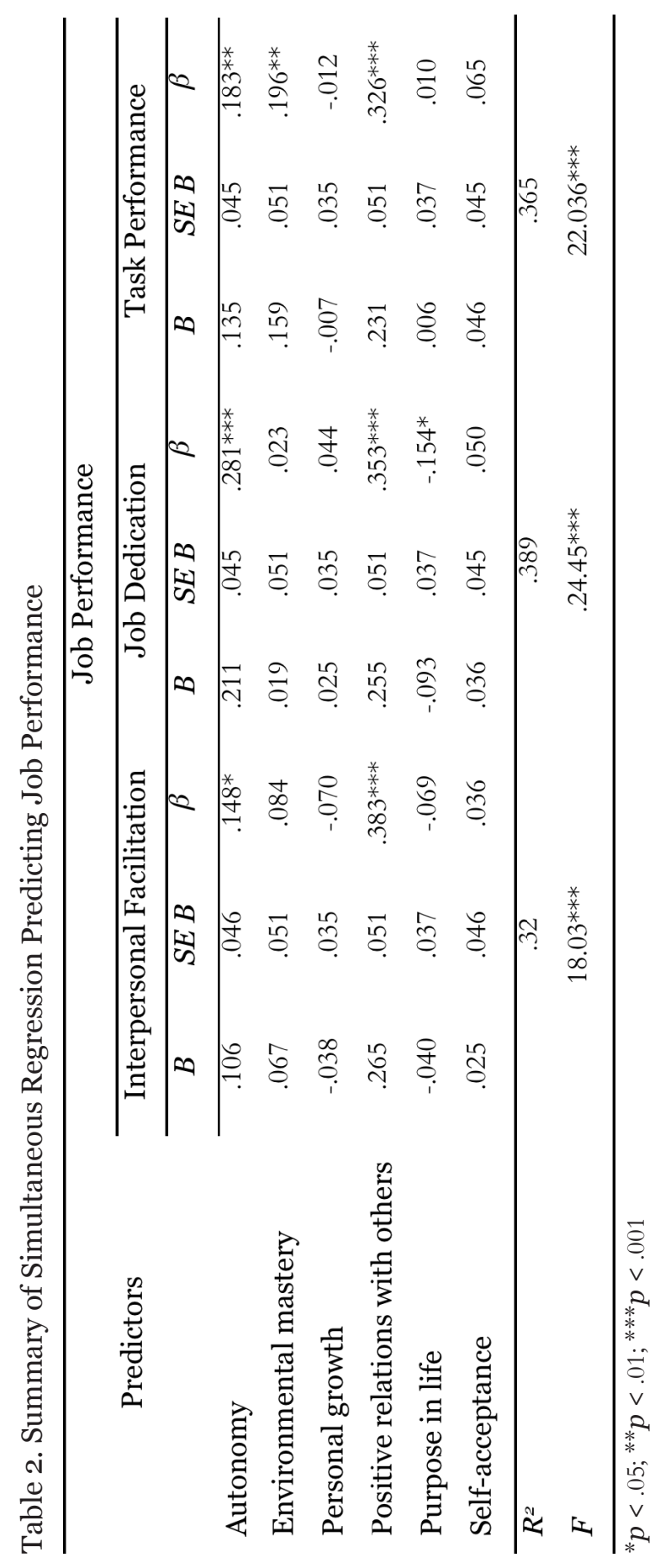




\section{DISCUSSION}

The main aim of this study was to investigate the psychometric properties of PWBS involving Filipino teachers in the Philippine context. A sample of 237 teachers from state-owned universities in the Philippines provided support to the multidimensional PWBS developed by Ryff (1989). With the various challenges affecting Filipino teachers, developing a research agenda advocating their psychological well-being is significant. This noble advocacy may start with the examination of the psychometric properties of PWBS.

The PWBS is a measure of psychological well-being put forth by Ryff (1989). Because of the importance of shedding light to psychological well-being of teachers in Asia, the idea of validating the instrument involving Filipino teachers in the Philippines emerged. Results showed that this is an adequate measure of PWB in a Filipino sample. The CFA result performed on the reduced version of PWBS fit adequately with data from Filipino teachers.

In terms of within-network validity, the results of the CFA showed adequate and acceptable fit indices suggesting the applicability of the Ryff's PWB scale among Filipino teachers. Additionally, the internal consistency of the six subscales were acceptable (from .62 - .85). The results suggest that the six different dimensions of PWBS are distinct. It can be recalled that an issue on the dimensionality of Ryff's scale has been raised where four (i.e., personal growth, purpose in life, selfacceptance, and environmental mastery) of the six factors are said to be indistinguishable and can be subsumed into a unidimensional factor (see Springer \& Hauser, 2006). The present results, however, appear to be in substantial agreement with the studies conducted by others providing support to a six-factor PWB (e.g., Ryff \& Keyes, 1995; van Dierendonck et al., 2008).

In terms of between-network validity, the correlations of the subscales of PWB with the three indices of job performance are within the expected direction which further provide evidence of the applicability of Ryff's model involving Filipino teachers. Except the subscale "purpose in life," all other subscales have positive correlations with the external criterion variables. Additionally, results of regression analyses suggest that the various dimensions of PWB can successfully 
explain significant amount of variance in predicting Filipino teachers' psychological and work outcomes (job performance). Noteworthy are teachers' autonomy and positive relations with others which served as consistent positive predictors across the three job performance indicators: interpersonal facilitation, job dedication, and task performance. This is interesting as it suggests that teachers' perception of control over making the decision (e.g., "I am not afraid to voice my opinion...”) and/or having smooth interpersonal relationships (e.g., "I know I can trust my friends and they know that they can trust me") translate into a perception of better job performance. It is essential therefore that administrators provide teachers with a sense of autonomy and pleasant school environment that facilitates smooth interpersonal relationships among teachers. This finding partly supports the hypothesis suggesting that dimensions of PWB can account for a significant amount of variance in the job performance of teachers.

\section{Limitations and Directions for Future Research}

A number of limitations are acknowledged here which should be considered in making sense of the results. First, the participants were not nationally representative and they were from two state-owned universities only. Perhaps future studies can consider extending the study involving teachers from private universities. Second, the non-translation of PWBS into Filipino version can also be a limitation. Although previous studies involving Filipino participants demonstrated that English and Filipino versions of a scale have comparable psychometric properties (see for example Ganotice, Bernardo, \& King, 2012; King et al., 2012), the availability of a Filipino version gives participants the chance to choose in which language they prefer to answer.

Despite these limitations, it is noteworthy that this study does not only provide psychometric validation data involving Filipino teachers but also extends the existing knowledge a little more by examining the ability of the six well-being dimensions in predicting job performance of teachers. While evincing that PWB can be represented by six dimensions: autonomy, environmental mastery, personal growth, 
positive relations with others, purpose in life, and self-acceptance, this study also clarified that PWB dimensions accounted for a significant amount of variance in predicting job performance. This provides empirical support to the link between psychological well-being and job performance (e.g., Sears et al., 2013), suggesting that one way to promote teacher work performance is through the promotion of activities that trigger their psychological well-being.

Building on these, research agenda in understanding the psychological well-being of Filipino teachers can now be conceptualized using the reduced version of Ryff's PWBS. Perhaps a research agenda can be defined to specifically provide understanding of Filipino teachers' state of psychological well-being, what contributes to their PWB, and how their PWB translates into their teaching performance as may be operationalized both in terms of execution of teaching-related duties (e.g., attendance, community service, teaching performance) and student academic gains as well. Additionally, a study that can be initiated is the differential PWB profile of Filipino teachers across locations and between school types (e.g., public vs private schools). It is important to note that the potential differences in teachers' PWB can be attributed to educational inputs in public and private Philippine schools (e.g., funding, infrastructure, class sizes). These are important lines of investigation that necessitates empirical support. These may sound practical but results can inform school policies to look into enhancing the well-being of teachers. Theoretically, while we know that psychological well-being can be an outcome (e.g., McInerney et al., 2014) or antecedent (Higgs \& Dulewicz, 2014), available literature is still scarce in terms of factors that contribute to the development of psychological well-being especially amongst teachers.

\section{Implications}

Practically, findings borne out from this study could provide useful input into enriching the future HR agenda for teachers. In particular, the findings imply the promotion of psychological wellbeing of Filipino teachers. Perhaps future HR development programs can especially target the three well-being dimensions that the teachers reported lowest: purpose in life, personal growth, and self-acceptance. 
Well-designed interventions that consider the various dimensions of well-being and enhance the psychological well-being of teachers are believed to help teachers cope with stress better. It may be important to recognize that a "one-size-fits-all" well-being program is not ideal as it should be tailored-fit to the needs of Filipino teachers.

This study concludes with a line from Horne (2011) emphasizing that "the promotion of employee psychological well-being is an intrinsic good for both individuals and organizations; on toward which we should all work." It is hoped that this effort to validate Ryff's PWB scale involving Filipino teachers is a step towards that direction and will stimulate further examination of psychological well-being as an important component of human functioning.

\section{REFERENCES}

Abbot, P., \& Wallace, C. (2010). Explaining economic and social transitions in post-Soviet Russia, Ukraine and Belarus: The social quality approach. European Societies, 12(5), 653-674.

Abbott, P., \& Sapsford, R. (2006). Life-satisfaction in post-Soviet Russia and Ukraine. Journal of Happiness Studies, 7(2), 251-287.

Anderson, J. C., \& Gerbing D. W. (1988). Structural equation modeling in practice: A review and recommended two-step approach. Psychological Bulletin, 103, 411-423.

Byrne, D. S. (1998). Complexity theory and the social sciences: An introduction. Psychology Press.

Cheng, S. T., \& Chan, A. C. M. (2005). Filial piety and psychological well-being in well older Chinese. Journal of Gerontology: Psychological Sciences, 61, 262-269.

Clarke P. J., Marshall V. M., Ryff, C. D., \& Wheaton B. (2001). Measuring psychological well-being in the Canadian study of health and aging. Int. Psychogeriatr, 13, 79-90. doi: 10.1017/S1041610202008013.

Diener, E. (2009). Conclusion: The well-being science needed now. Social Indicators Research Series, 37, 267-271. doi: 10.1007/978-90-481-2350-61

Esposito, C. (1999). Learning in urban blight: School climate and its 
effect on the school performance of urban, minority, low-income children. School Psychology Review, 28, 365-377.

Finney, S. J., \& DiStefano, C. (2006). Non-normal and categorical data in structural equation modeling. In G. R. Hancock \& R. O. Mueller (Eds.), Structural equation modeling: A second course (pp. 269314). Greenwich, CT: Information Age.

Fischer, R. (2004). Standardization to account for cross-cultural response bias: A classification of score adjustment procedures and review of research in JCCP. Journal of Cross-Cultural Psychology, 35, 263-282.

Fredrickson, B. L. (2001). The role of positive emotions in positive psychology: The broaden-and-build theory of positive emotions. American Psychologist, 56(3), 218-226. doi:10.1037/0003-066X.56.3.218

Gamboa, R. (2014, September 25). Paying tribute to the Filipino teacher. The Philippine Star. Retrieved from http://www.philstar. com/business/2014/o9/25/1372753/paying-tribute-filipinoteacher.

Gandy, W. M., Carter, C., Pope, J. E., \& Rula, E. Y. (2014). Well-being and employee health: How employees' well-being scores interact with demographic factors to influence risk of hospitalization or an emergency room visit. Population Health Management, 7(1), 1320. doi:10.1089/pop.2012.0120

Ganotice, F. A., Bernardo, A. B., \& King, R. B. (2012). Testing the factorial invariance of the English and Filipino versions of the Inventory of School Motivation with bilingual students in the Philippines. Journal of Psychoeducational Assessment, 30, 298303. doi:10.1177/0734282911435459.

Ganotice, F. A., Downing, K., Mak, T., Chan, B., \& Lee, W. Y. (2015). Translation and validation of the Chinese version of Parent-Child Relationship Inventory (PCRI-C) in Hong Kong. Child Indicators Research, 8(3), 657-670. doi:10.1007/s12187-014-9270-6

Hambleton, R. K. (2001). The next generation of the ITC test translation and adaptation guidelines. European Journal of Psychological Assessment, 17(3), 164-172. doi:10.1027//1015-5759.17.3.164

Haynes, N. M, Emmons, C., \& Ben-Avie, M. (1997). School climate 
as a factor in student adjustment and achievement. Journal of Educational and Psychological Consultation, 8, 321-329.

Higgs, M., \& Dulewicz, V., (2014). Antecedents of well-being: A study to examine the extent to which personality and emotional intelligence contribute to well-being. The International Journal of Human Resource Management, 25, 718-735. doi:10.1080/09585192.2013.815253

Hone, L., Jarden, A., \& Schofield, G. (2014). Psychometric properties of the Flourishing Scale in a New Zealand sample. Social Indicators Research, 119, 1031-1045.

Horne, A. (2011, July 6). Getting to the hearth of employee well-being. Retrieved from http://positivepsychologynews.com/news/ amanda-horne/2011070618473.

Hoy, W. K., Hannum, J., \& Tschannen-Moran, M. (1998). Organizational climate and student achievement: A parsimonious and longitudinal view. Journal of School Leadership, 8, 336-359.

Hu, L., \& Bentler, P. M. (1999). Cutoff criteria for fit indexes in covariance structure analysis: Conventional criteria versus new alternatives. Structural Equation Modeling, 6, 1-55.

Huppert, F. A., Baylis, N., \& Keverne, B. (Eds.). (2005). The science of well-being. Oxford, UK: Oxford University Press.

Johnson, S., Cooper, C., Cartwright, S., Donald, I., Taylor, P., \& Millet, C. (2005). The experience of work-related stress across occupations. Journal of Managerial Psychology, 20, 178-187. doi:10.1108/02683940510579803

Kafka, J., \& Kozma, A. (2002). The construct validity of Ryff's Scales of Psychological Well-Being (SPWB) and their relationship to measures of subjective well-being. Social Indicators Research, 57, 171-190.

Kállay, E., \& Rus, C. (2014). Psychometric properties of the 44-item version of Ryff's Psychological Well-Being Scale. European Journal of Psychological Assessment, 3o(1), 15-21. doi:10.1027/1015-5759/aooo163

King, R. B., \& Ganotice, F. A. (2013). Student motivation as hierarchical and multidimensional: Cross-cultural validation of personal investment theory in the Philippines. Universitas Psychologica, 12, 685-698. doi:10.11144/Javeriana.UPSY12-3.smhm. 
King, R. B., Ganotice, F. A., \& McInerney, D. M. (2012). Crosscultural validation of the Sense of Self ( $\mathrm{SoS})$ Scale in Chinese and Filipino settings. Child Indicators Research, 5, 719-734. doi:10.1007/s12187-011-9117.

Kishida, Y., Kitamura, T, Gatayama, R., Matsuoka, T., Miura, S., \& Yamabe, K. (2004). Ryff's psychological well-being inventory: Factorial structure and life history correlates among Japanese university students. Psychol Rep., 94(1), 83-103.

Kyriacou, C. (2001). Teacher stress: Directions for future research. Educational Review, 53, 28-35.

Lindfors, P., Berntsson, L., \& Lundberg, U. (2006). Factor structure of Ryff's psychological well-being scales in Swedish female and male white-collar workers. Personality and Individual Differences, 4O, 1213-1222.

Maneesriwongul, W., \& Dixon, J. K. (2004). Instrument translation process: A methods review. Journal of Advanced Nursing, 48, 175-186.

Marsh, H. W. (1997). The measurement of physical self-concept: A construct validation approach. In K. Fox (Ed.), The physical selfconcept: From motivation to well-being (pp. 27-58). Champaign, IL: Human Kinetics.

McInerney, D. M., Ganotice, F. A., King, R. B., Morin, A. J. S., \& Marsh, H.W. (2014). Teachers' commitment and psychological well-being: Implications of self-beliefs for teaching in Hong Kong. Educational Psychology, 35(8), 926-945. doi:10.1080/01443410 .2014 .895801

Ryan, R. M., \& Deci, E.L (2001). On happiness and human potentials: A review of research on hedonic and eudaimonic well-being. Annual Review Psychology, 52, 141-161.

Ryff, C. D. (1989). Happiness is everything, or is it? Explorations on the meaning of psychological well-being. Journal of Personality and Social Psychology, 57, 1069-1081.

Ryff, C. D. (2014). Psychological well-being revisited: Advances in the science and practice of eudaimonia. Psychotherapy and Psychosomatics, 83, 10-28. doi:10.1159/000353263

Ryff, C. D., \& Keyes, C. (1995). The structure of psychological wellbeing revisited. Journal of Personality and Social Psychology, 
69, 719-727.

Ryff, C. D., \& Singer, B. H. (1998). The contours of positive human health. Psychological Inquiry, 9, 1-28.

Ryff, C. D., \& Singer, B. H. (2006). Best news yet on the six-factor model of well-being. Social Science Research, 35, 1103-1119.

Sears, L. E., Shi, Y., Coberley, S. R., \& Pope, J. E (2013). Overall wellbeing as a predictor of health care, productivity, and retention outcomes in a large employer. Population Health Management, 16(6), 397-405. doi:10.1089/pop.2012.0114

Seligman, M. (2011). Flourish. New York: Simon \& Schuster.

Seligman, M., \& Csikszentmihalyi, M. (2000). Positive psychology: An introduction. American Psychologist, 55(1), 5-14. doi:10.1037/0003-066X.55.1.5

Silva, A. J., \& Caetano, A. (2011). Validation of the flourishing scale and scale of positive and negative experience in Portugal. Social Indicators Research, 110(2), 469-447. doi:10.1007/s11205-011-9938-y

Sirigatti, S., Stefanile, C., Giannetti, E., Iani, L., Penzo, I., \& Mazzeschi, A. (2009). Assessment of factor structure of Ryff's Psychological Well-being scales in Italian adolescents. Bollettino di Psicologia Applicata, 56(259), 25930-25950.

Springer, K. W., \& Hauser, R. M. (2006). An assessment of the construct validity of Ryff's scales of psychological well-being: Method, mode, and measurement effects. Social Science Research, 35, 1080-1102.

Stevens, J. P. (2002). Applied multivariate statistics for the social sciences (4th ed.). Mahwah, NJ: Lawrence Erlbaum.

Torrevillas, D. M. (2013, February 7). Higher pay for public school teachers. The Philippine Star. Retrieved from http://www. philstar.com/opinion/2013/02/07/905890/higher-pay-publicschool-teachers

Travers, C. J., \& Cooper, C. L. (1996). Teachers under pressure: Stress in the teaching profession. New York, NY: Routledge.

van Dierendonck, D., Díaz, D., Rodríguez-Carvajal, R., Blanco, A., \& Moreno-Jiménez, B. (2008). Ryff's six-factor model of psychological well-being: A Spanish exploration. Social Indicators Research, 87(3), 473-479. 
Van Scotter, J. R., \& Motowidlo, S. J. (1996). Interpersonal facilitation and job dedication as separate facets of contextual performance. Journal of Applied Psychology, 81, 525-531. doi:10.1037/0021-9010.81.5.525

Vazquez, C. Hervas, G., Rahona, J., \& Gomez, D. (2009). Psychological well-being and health: Contributions of positive psychology. Annuary of Clinical and Health Psychology, 5, 15-27. 